\title{
Espaços e Imagens da Gentrificação no Centro de São Paulo ${ }^{1}$
}

\section{Fabio Raddi Uchôa}

Doutor em Ciências da Comunicação pela ECA/USP. Desde o início de 2014, desenvolve pesquisa de pós-doutorado junto ao Programa de Pós-Graduação em Imagem e Som da UFSCar, explorando as representações de São Paulo na produção televisiva recente. Faz parte do Conselho Deliberativo Sociedade Brasileira de Estudos de Cinema e Audiovisual (SOCINE), sendo também um dos co-editores da Revista Rebeca. E-mail: raddiuchoa@gmail.com ${ }^{1}$ Uma versão anterior deste texto foi apresentada no Grupo de Pesquisa "Cultura das Mídias", do XXIII Encontro Anual da Compós, que ocorreu de 27 a 30 de maio de 2014, na Universidade Federal do Pará, em Belém.
Resumo: Dos anos 1990 à atualidade, de maneira intensificada com os preparativos para a Copa do Mundo 2014 (FIFA), o centro de São Paulo é foco de ações de requalificação urbana. Denominado por alguns autores de "gentrificação", tratase de um processo de substituição dos habitantes de uma região, por aqueles de uma classe mais abastada, associado a modificações físicas, sociais, culturais e imagéticas. A presente pesquisa, em termos figurativos, analisa a reverberação de tal processo na produção audiovisual contemporânea, a partir de dois grupos particulares de imagens: a) a publicidade televisiva realizada pelo Grupo INK e b) a minissérie Amor em 4 atos (2011).

Palavras-chaves: Gentrificação; Publicidade; Minisséries.

\section{Title: Spaces and Images of the Gentrification in São Paulo's Center.}

Abstract: From the 1990s to the present, intensified by the preparations for the World Cup 2014 (FIFA), Sao Paulo's centre is the focus of urbane requalification Actions. Called by some authors "gentrification", it's a process of inhabitant substitution of a region, for those of a more affluent class, associated with physical, social, cultural and imaging modifications. This research analyses the influence of this process on the contemporary audiovisual production, by means of two particular groups of images: a) the television advertising produced by Grupo INK, and b) the miniserie Amor em 4 atos (2011).

Keywords: Gentrification; Advertising; Miniseries.

\section{Introdução}

Qualquer esforço para o rearranjo do espaço na cidade é também um esforço de representação visual. (ZUKIN, 1995: 24)

De tanto filmá-las, o cinema não só revela alguma coisa do destino cinematográfico das cidades (a gênese urbana do cinema), mas o transforma: pouco a pouco, a cidade filmada substitui toda a cidade real, ou melhor, se torna o real de toda a cidade. (COMOLLI, 2004: 545)

O grande estardalhaço, causado por ações policiais e demolições na região da Luz, centro de São Paulo, faz parte de uma experiência urbana e imagética recente. São recorrentes as mega-operações policiais, apoiadas por parte da imprensa, insistindo na remoção de uma massa móvel de habitantes "indesejáveis" - centenas de químico-dependentes, moradores de rua e catadores de materiais recicláveis. Para 
os moradores e freqüentadores da região, foi também impactante a demolição da antiga rodoviária, que abriu espaço para uma espécie de campo de concentração a céu aberto - onde os próprios habitantes expulsos, rodeados pela vigilância policial, carregavam as entranhas de ferro da construção demolida, buscando tirar algum dinheiro para a própria sobrevivência. Paralelamente a tais eventos, as Viradas Culturais, associadas aos grandes meios de comunicação de massa, promovem uma nova cidade, propositalmente marcada pela diversidade cultural e pela inexistência de conflitos sociais. Isso se desenvolve, sobretudo, por meio da TV, onde, por um lado, os jornais sensacionalistas promovem a ética da vigilância, substituindo o estado de bem estar social por um estado penal, e por outro lado, as propagandas e minisséries reverberam o processo em curso, ora criando uma cidade apaziguada, ora sugerindo o confronto e processos de re-apropriação criativa.

Estamos diante de um processo típico das cidades no contexto do capitalismo, denominado de "requalificação urbana" ou "gentrificação", que é acelerado em cidades-sede de grandes eventos esportivos; a exemplo de Barcelona, Rio de Janeiro e, com a Copa do Mundo FIFA 2014, também São Paulo. O trabalho aqui proposto é multidisciplinar, analisando paralelamente o fenômeno físico, de produção do espaço da cidade, e o fenômeno imagético-narrativo, de criação de uma cidade imaginada. Dialoga-se aqui com a proposta de Jean-Claude Bernardet, no curso Cinema e metrópole: o caso paulistano (1993), buscando as interfaces entre produção audiovisual e arquitetura, indicando também as possibilidades de figuração e contra-figuração, de processos urbanos nas imagens da São Paulo do século XX, com especial atenção ao centro da cidade. Foi eleito um grupo particular de imagens - publicidades produzidas pelo Grupo INK (1996-2014) e a minissérie Amor em 4 atos (2011) - que se ambientam no centro de São Paulo e possuem sintonia figurativa, imaginária e ideológica ante ao processo de requalificação urbana. Em termos de análise, ao identificar semelhanças, repetições e confrontos, entre a produção do espaço e a produção de imagens, este trabalho dialoga com a análise figurativa proposta por Aumont (1996) e Nichole Brenez (1998; 2006). Ou seja, buscam-se os traços de uma economia figurativa, em suas reverberações entre a morfologia da imagem, as suas qualidades formais, o tratamento dos motivos e as sintonias físico-temáticas de tais traços ante ao processo de requalificação urbana em curso - que pode ser de identidade ou diferença.

Por outro lado, são também contempladas as relações entre imagens e sociedade, tomando a reprodução do espaço como criação de imagens e ideologias (Cf. ZUKIN, 1995), bem como identificando tipos de deslocamento particulares, existentes entre a cidade vivida e a cidade reproduzida pelas imagens (Cf. COMOLLI, 2004).

\section{Gentrificação - conceituação e presença no centro de São Paulo}

A definição conceitual da gentrificação deve levar em conta as origens do termo, entre as ciências sociais anglo-saxônicas dos anos 1960, e a respectiva ampliação, durante as décadas seguintes, num contexto neoliberal de gestão das cidades. O termo foi usado, inicialmente, pela socióloga britânica Ruth Glass (1963), para caracterizar um fenômeno típico de Londres e cidades inglesas: uma ação pontual, realizada por agentes privados, que resulta na retomada das regiões centrais pela classe média londrina e, consequentemente, na revalorização e modificação do perfil social de seus habitantes (GLASS, 1963); ou seja, um processo de substituição de classes sociais, associado à valorização do espaço. Ao longo da segunda metade do século XX, o fenômeno dissemina-se em outras cidades do ocidente, suscitando novas interpretações e a ampliação do termo. Assim, para Hamnet, a gentrificação será vista como "um processo ao mesmo tempo físico, econômico, social e cultural." (HAMNET, 1995: 16) Mais recentemente, Neil Smith pensa no fenômeno como o resultado do desenvolvimento desigual, e que se transforma numa estratégia urbana global, a serviço de um urbanismo neoliberal (SMITH, 2005), num contexto de mundialização do capital financeiro. Não se 
${ }^{2}$ Gentrificação ocorrida no bojo de Planejamentos Urbanos Estratégicos. Noção de gentrificação sugerida por Otilia Arantes: para ela, a gentrificação seria um dos desdobramentos do planejamento urbano estratégico (por meio de Planos Estratégicos), que transfigura cidades no contexto de mega-eventos esportivos, como Olimpíadas, Copas do Mundo e Jogos Panamericanos.

${ }^{3}$ Exemplo de Barcelona, que é totalmente modificada durante os últimos 30 anos, especialmente a partir das Olimpíadas de 1992 - e posteriores eventos culturais; transformando a cidade num local atrativo para investimentos e o turismo. trata mais de um fenômeno pontual, mas sim de um procedimento dirigido e generalizado, associado a projetos de "regeneração" urbana. Entre os traços de tal gentrificação generalizada, Smith (2006) identifica: a influência do processo em setores culturais e comerciais, as parcerias púbico-privadas, a presença de capital global, bem como a forte repressão, seguida pelo engajamento por parte dos moradores deslocados, ou movimentos políticos de oposição à gentrificação.

Para se questionar as relações entre (re)produção do espaço e (re)produção de imagens, são importantes as teorias que pensam nas relações entre cultura, cidade e capitalismo, firmadas a partir do final dos anos 1960. Em tal contexto, denominado por alguns de cultural turn, a cultura torna-se um grande negócio, uma "mercadoria vedete da sociedade espetacular" (DEBORD, 1992: 191), assumindo um papel fundamental nas estratégias de revitalização urbana. Isso inclui o aumento da confiabilidade dos investimentos, a criação de consensos e o subsídio para a venda do espaço urbano, por meio de mega operações do imagemarketing. Ocupando o vazio deixado pela crise das políticas do welfare state, a cultura apresenta-se como um falso antídoto, usado pelas elites financeiras como "isca ou imagem publicitária" (ARANTES, 2012: 47), com seus investimentos em atividades e equipamentos culturais. No livro Berlim e Barcelona, duas imagens estratégicas, a "gentrificação estratégica"2 é pensada por Otilia Arantes no contexto das cidades-sede de grandes eventos esportivos: são cidades-imagem, que devem ser refeitas, reembaladas e relançadas; assim, as mesmas alimentam um mercado de imagens, cuja ação reafirma a cidade como máquina de fazer negócios e a cultura como mercadoria privilegiada ${ }^{3}$. Outro traço, próprio à capitalização da cultura em cidades em vias de gentrificação, é a ativação de um mercado de bens simbólicos. No livro The culture of cities, a socióloga Sharon Zukin identifica as bases e o funcionamento de tal mercado, que articula a produção do espaço e a criação de representações visuais da cidade, com influências sobre a militarização do espaço público e a estetização do medo.

No caso de São Paulo, dos anos 1990 à atualidade, percebe-se um centro em vias de gentrificação, com uma série de elementos e pressupostos já consolidados, entre os quais: a) uma legislação urbana propícia aos especuladores imobiliários; b) investimentos do Governo do Estado e da Prefeitura em instituições e eventos culturais; c) o aumento dos conflitos, da vigilância policial e da criação de discursos higienizantes; d) a criação de uma "cidade revanchista" que, como indicado por Neil Smith (1996), reprime as minorias opositoras à gentrificação - como os moradores de rua, os químico-dependentes e os movimentos populares por moradia; e) bem como o engajamento de entidades civis e representantes das classes sociais prejudicadas, na resistência ante a transformação e re-significação dos espaços em questão.

Durante os últimos 20 anos, a cidade se insere num tipo de gestão compatível com o neoliberalismo - são realizadas intervenções de "requalificação", a partir de parcerias público-privadas, que promovem o upgrade cultural da região, gerem o espaço como mercadoria a ser valorizada a despeito das dinâmicas sociais ali existentes, fomentando também discursos higienizantes, ações de vigilância policial e a remoção pontual da população menos abastada.

No âmbito da política urbana municipal, as principais intervenções, a contribuir para a criação de uma "linguagem" da gentrificação (SMITH, 2006: 72), se dão por meio das chamadas Operações Urbanas, instrumentos jurídico/urbanísticos existentes na cidade desde os anos 1990 e regulamentados pelo Plano Diretor Estratégico (SEMPLA, 2004) e por leis municipais específicas. Trata-se de intervenções pontuais, 
${ }^{4}$ Operação Urbana Centro. Lei 12.346 de 6 de junho de 1997.

${ }^{5}$ PMSP. Programa de Ação Centro - BID. Projeto Nova Luz. São Paulo: Secretaria Municipal de Planejamento; SEMPLA; EMPURB, 2005. a partir de parcerias público-privadas, cujos projetos formalizam-se por meio de exceções na legislação urbana. Na capital paulista, como sugerido por Maricato e Ferreira (2002), a aplicação de tais instrumentos privilegia os interesses dominantes e a lógica da especulação imobiliária, reproduzindo a exclusão sócio-econômica e privatização da esfera pública próprios à sociedade brasileira. Para nós, é de especial interesse a Operação Urbana Centro ${ }^{4}$, que existe desde 1997 e inclui entre seus objetivos: a recuperação da área central da cidade, tornando-a novamente atraente para investimentos imobiliários, comerciais, turísticos e culturais. Por meio de tal Operação, realizaram-se projetos que contribuem para a reativação do potencial cultural da área (museus e áreas públicas para eventos culturais), a revalorização de edifícios públicos e, em termos gerais, o reaquecimento do mercado imobiliário da região. O perímetro de abrangência da referida Operação Urbana engloba os chamados "centro novo" e "centro velho" e partes dos bairros do Glicério, Brás, Bexiga, Vila Buarque e Sta. Ifigênia.

Entre tais intervenções, que veiculam um discurso da "requalificação", com a idéia de que há algo indesejado a ser retirado da região, muitas colaboram para a mudança do uso social dos espaços e a criação de uma nova imagem da cidade. Em algumas de tais intervenções, perceberam-se tentativas de confronto e de tensão, promovidas por parte da sociedade civil. Neste contexto, alguns projetos podem ser citados. Em 1999, nas imediações da "cracolândia", a antiga Estação Julio Prestes foi reformada, originando a Sala São Paulo, num projeto com ares civilizatórios, constituindo uma nova fronteira no processo de revitalização por meio do investimento cultural (Cf. WISNIK; FIX et all.; 2001). No Projeto Nova Luz $(2005)^{5}$, previa-se a desapropriação e demolição de 13 quadras urbanas na região da Luz, num processo de remodelação do uso e das funções do espaço, com o início de forte presença policial e o afastamento da população de menor poder aquisitivo. Em 2013, o Projeto Nova Luz foi revogado pelo projeto de lei 282/2013, proposto pelo vereador Nabil Bonduki, sob a alegação de que não houve o devido debate e participação de diferentes segmentos da sociedade civil -, ignorando os usos pré-existentes, e sem garantir a manutenção da população e dos empregos no perímetro. Em 2010, iniciou-se a demolição da antiga rodoviária, para a construção do majestoso Complexo Cultural Teatro de Dança, planejado pelos suíços Herzog \& Meuron. No início de 2014, depois de diversas desapropriações, os investimentos públicos foram paralisados, sob um debate acerca dos altos custos da obra. Em 2012, finalizaram-se as reformas da Praça Roosevelt, com a valorização de um pólo teatral a partir de um espaço de tensões, que acolhe novos coletivos e, ao mesmo tempo, impõe-se por meio dos vazios e da vigilância policial. Entre os anos 2005 e 2013, grandes quermesses culturais policiadas, como as Viradas Culturais realizadas pelo Governo do Estado, promoveram a divulgação e o fluxo de potenciais consumidores, em torno de diversos de tais espaços.

\section{As figurações da gentrificação.}

Aparentemente, o processo acima referido não se restringe ao espaço urbano, apresentando reflexos sobre as imagens produzidas da cidade. Como sugerido por Jean-Louis Comolli, em "La ville filmée" (2004), a cidade representada é uma reconstituição da cidade vivida: as realizações audiovisuais alteram o mundo, a partir de uma representação que o "desloca", provocando uma impressão de realismo, mas também de irrealidade. A partir de um processo imaginário, porém, a cidade filmada passa a substituir a própria cidade real, dizendo algo sobre seu destino e inspirando o homem que caminha pelas ruas.

Por meio das imagens que serão aqui analisadas, busca-se definir traços da São Paulo imaginária atual e suas sintonias/confrontos ante ao processo de gentrificação. Na gama de imagens produzidas em torno do centro da cidade, identificamos duas tendências que podem apresentar-se de maneira polarizada ou mesclada: por um lado, imagens que afirmam a cidade e a si mesmas como 
${ }^{6}$ As duas categorias, de obra e produto, aqui aplicadas à cidade e às imagens, que reverberam as idéias de valor de uso e valor de troca, são debatidas com profundidade por Henri Lefebvre, em La presence et l'absence: contribution a la theorie des representations. (LEFEBVRE, 1980).

\footnotetext{
${ }^{7}$ Dimensão do encontro e da criação do novo, teorizada por Henri Lefebvre em Le droi a la ville (1968).

${ }^{8}$ No livro O ornamento da massa (1927), arquiteto e teórico do cinema Siegfried Kracauer aborda a noção de ornamento, enfatizando que o movimento mecânico e linear das tillergirls, ordenadamente aplaudido pelas massas, é o reflexo estético de uma forma de pensamento taylorista, próprio ao período. Assim como as pernas das tillergirls, o caráter serial das operações promovidas pelos comerciais e minisséries colaboram para a construção de figuras, particularmente caracterizadas por simetrias - é necessário definir as formas de pensamento, bem como os padrões de relação estabelecidos com a cidade, presentes em tais produtos audiovisuais.
}

produto, explicitando o caráter serial e de revalorização do mercado imobiliário em curso; por outro lado, imagens marcadas pela criatividade, pela diferença e pelo encontro, afirmando a cidade e a si mesmas como obra, espaços lúdicos do homem que se re-significa a si mesmo ${ }^{6}$.

Partiremos de duas modalidades de imagens: a) filmes publicitários e b) uma minissérie televisiva, Amor em 4 atos, ambos realizados em colaboração com o Grupo INK.

O primeiro grupo de imagens, a publicidade televisiva, pode ser pensado como um tipo de produto cultural particularmente serial e reificado, baseado na padronização de procedimentos. Nele, há maior predominância do pólo produto, com certas tensões, propiciadas pela criatividade de alguns dos publicitários, que atribuem complexidade eambigüidade às mensagens publicitárias. Em tal conjunto, predominantemente, verifica-se um centro urbano apaziguado e consumível, a partir de lógicas narrativas que reverberam a especulação imobiliária e os investimentos culturais - construídos em sintonia com as estratégias do Estado, das elites financeiras e por parte dos meios de comunicação de massa. Tratamos aqui de figurações da gentrificação, presentes em propagandas televisivas ambientadas no centro de São Paulo e, em particular, aquelas de automóveis, bancos e campanhas para o próprio Governo.

Por outro lado, no segundo grupo de imagens, a minissérie televisiva Amor em 4 atos permite uma complexidade maior ante ao pólo produto, propondo uma re-apropriação de maior teor lúdico, com estratégias pautadas pela densidade psicológica e por diálogos com o universo do melodrama. Assim como Amor em 4 atos, muitas das minisséries apresentadas pela TV Globo na última década apresentam uma classe média, de artistas e profissionais liberais, que repovoa o centro, tomando-o como espaço das realizações sentimentais e pessoais.

Na abordagem destes produtos televisivos, definiremos e aprofundaremos alguns traços em particular: a) o modo como projetam espaços-foco de reformas urbanas, ou imagens-ícones da região central, colocando-os como palco das ações e projeções do desejo; concebendo um novo mapa de cidade, que é reproduzido a esmo, com tensões e sintonias ante aos fluxos humanos e significados, produzidos no contexto de mega-eventos, como as Viradas Culturais (2005-2013); b) sua colaboração para a criação de um imaginário gentrificante, que inclui a higienização e o confronto; ao afirmarem-se enquanto produto, avançam com a substituição dos conflitos sociais existentes por uma nova imagem de cidade higienizada e desejada como local de investimento, moradia e lazer. Neste sentido, aproximam-se de um olhar higienizante, que apaga exatamente os espaços do conflito e da reprodução da vida social; ao reverberarem sua condição de obras, atentam para um imaginário próprio ao confronto e à criação do novo; c) sua aproximação ou distanciamento ante a um uso particular da cultura, como símbolo de status e distinção, que acena para investimentos imobiliários, promovendo uma substituição imaginária das classes e práticas sociais existentes na "vida cotidiana"7; d) do ponto de vista narrativo, sua sintonia com a repetição serial que, em termos de circulação e de padrões visuais, permite aproximá-los da idéia de "ornamentos" 8 urbanos, que figuram ações e formas de pensamento, próprias ao momento atual - de investimentos em cultura e especulação financeira, ou então, de criação de tensões e ruídos para o transcurso de tais ações. 


\section{Publicidade: o caso Grupo INK}

${ }^{9}$ Até 2013, tinha como principais sócios: Paulo Schimdt, Tadeu Jungle, Antonio Carlos Accioly e Marily Raphul. Em 2011, com 15 anos de existência, o grupo havia realizado mais de sete mil filmes publicitários, seis longa metragens, quatro séries para tv aberta, dois reality shows e um talk show; além de 150 produtos culturais e exposições. (fonte: jornal PropMark. Cf. "Grupo INK comemora 15 anos de mercado." 22 de agosto 2011. Disponível em: http:// old.propmark.com.br). Em agosto de 2013, Accioly deixa a empresa; a mesma é enxugada e volta ao nome original "Academia de filmes" - composta apenas pelas empresas Academia de filmes, Academia de cultura e Base 7. A Margarida Filmes é incorporada pela Academia de Filmes, que atualmente conta entre seu quadro de diretores e publicitários: André Pellenz, Caio Rubini, Duda Meirelles, Fernanda Weinfeld, Luigi Dias, Matheus Siqueira, Marco Aslan, Marcos Jorge, Marcus Tornovsky e Tadeu Jungle.

10 Comerciais para marcas como Brahma, Carefree, Gillette, Ponto Frio, Sony Ericsson, Motorola, Knorr, Mitsubishi, Bis, Nivea, Pantene, Garnier, Citroën e JAC Motors; bem como teasers de abertura de algumas novelas globais.

11 Trabalhos para Natura, Coca-Cola, Fiat, Ford, Skol, Petrobras.

12 Projetos culturais como o Museu TAM, e o Museu do Futebol.

${ }^{13}$ Direção Tadeu Jungle.

${ }^{14}$ Link: http://vimeo.com/37386682.

${ }^{15}$ A manipulação das imagens (enquadramentos e efeitos visuais) permite definir quais os edifícios simbólicos que, porventura, deverão ganhar destaque.
No caso da publicidade e das minisséries, produtos televisivos com fronteiras cada vez menores, a aproximação ante ao processo de venda da cidade é grande. Isso se dá: em termos do tipo de racionalidade presente na produção, bem como quanto às ideologias, criadas a partir de artifícios narrativos particulares. No âmbito de um mercado de produção de imagens da cidade, em São Paulo, ganham força aquelas empresas que flexibilizam a produção, concentrando num mesmo núcleo a realização de produtos os mais variados possíveis. Dentre eles, podese destacar um aglomerado de empresas denominado Grupo INK ${ }^{9}$ (1996-2014), que engloba 5 produtoras (Academia Filmes, Margarida Filmes ${ }^{10}$, Colméia ${ }^{11}$, Base $7^{12}$, Academia de Cultura e llegal FX) divididas entre a produção de publicidade, minisséries televisivas, filmes de longa metragem, e até mostras, exposições e eventos culturais. Seus associados participaram da realização de minisséries como Amor em 4 atos (2011), e longa metragens como Amanhã nunca mais (2011) ambos ambientados em São Paulo; além de milhares de filmes publicitários. Entre os financiadores de materiais publicitários ambientados no centro, encontramos: a prefeitura, grande bancos e empresas de automóveis.

Durante a última década, a Margarida Filmes e a Academia de Filmes, membros do Grupo INK, incluíram entre suas produções comerciais de carros, com imagens de uma São Paulo global, reformulada a partir de dois processos em particular: primeiramente, a supressão digital da identidade, buscando diálogos ecléticos com outras capitais internacionais; em segundo, a ênfase a imagens-ícones, ou espaços emblemáticos, apenas de maneira pontual, ativando um potencial imaginário turístico da capital. A partir destes dois processos, verifica-se uma cidade reconfigurada, cujas imediações centrais tornam-se o palco de lançamento de grandes máquinas. É o caso de algumas das publicidades de Cristiano Metri, cujo estilo é marcado por uma mescla particular, entre imagens urbanas e posterior trabalho de animação computadorizada.

Em "Bufalos"14, encomendado pela GM e realizado por Cristiano Metri, uma centena de búfalos passam em frente à praça do Patriarca, avançando no sentido do Mosteiro São Bento, numa cidade com certo glamour americanizado, e chegando em uma casa de campo, que poderia ser no velho oeste americano. $O$ grande mote é a comparação entre a centena de búfalos e o carro a ser vendido. A construção da cidade em si, porém, é ainda mais importante: incensada, estilo retrô, com toda uma manipulação computadorizada (pós-produção), que limpa ou ressalta, aquilo que deve ou não ser visto. Verifica-se o germe de algo bastante comum em outras propagandas: uma tendência ao apagamento, das sujeiras e da presença dos transeuntes da própria cidade. Os enquadramentos tendendo à proximidade e ao chão, a fragmentação dos planos, bem como os movimentos de câmera, impedem uma identificação súbita da cidade - o espectador paulista sabe, indiretamente, que o local desbravado pela centena de búfalos é o final do Viaduto do Chá, situado entre a Prefeitura e a Praça do Patriarca. Temos assim mais um dos traços básicos de tais comerciais: evocar o status de determinados edifícios e construções, por meio de uma alusão indireta ${ }^{15}$. Muitos edifícios e construções emblemáticos chegam a ser mostrados, mas a partir de enquadramentos não usuais, impedindo a direta identificação por parte do espectador. Tal olhar, que tende à limpeza da cidade, tem entre seus referenciais uma busca por simetrias arquitetônicas, atenta a obras de arquitetos como Ramos de Azevedo - uma incorporação estilística da arquitetura eclética, que funde certas referências européias, incluindo o neoclássico. No caso deste comercial, isso é ainda rarefeito: há somente algo de simétrico nas janelas de um edifício, ou então no beiral de um viaduto. Tal tendência é marcante em outros comerciais, tornando-se mais uma das bases do processo de des-identificação, ou apagamento, da cidade vivida. 
${ }^{16}$ Link: http://vimeo.com/50076961.

${ }^{17}$ De acordo com Frugoli Jr. “Uma reorganização desse sistema incidiria sobre essa massa, distribuindo-a para outras regiões, o que dessa forma poderia reduzir tanto a mendicância, quanto o comércio informal. Isso propiciaria, por conseqüência, o atendimento do "verdadeiro interesse popular", entendido como os empregados das empresas - que constituem, por sinal, um habitual público-alvo de revitalizações urbanas em metrópoles do Primeiro Mundo." (FRUGOLI JR., 1997).
Em outra das publicidades realizadas por Cristiano Metri, neste caso encomendada pela seguradora Líder, para a venda de um seguro para acidentes de trânsito ("Seguro DPVAT"16), a tendência à des-identificação da cidade associase ao tema das normas, da segurança e do deslocamento físico pelo centro. Nela, é exatamente a norma, ou seja, o boneco de uma placa de transito, que toma vida para salvar uma criança do atropelamento. O perigo, por sua vez, é representado por um Maverick vermelho. Para além da venda de um seguro, estão em questão o direito de ir e vir, bem como a vigilância da região central, que são assegurados por uma ação coletiva de bonecos de placas de trânsito. O fluxo percorrido poderia ser aquele de uma viatura policial. A construção do trajeto, novamente, se dá por meio de estratégias de des-identificação do centro, notando-se apenas a relativa persistência do prédio do Banespa - que sugere uma aliança entre o capital financeiro e a efetividade da vigilância promovida pelo Seguro DPVAT.

Neste caso, o processo de des-identificação envolve: enquadramentos que negam o contexto geral dos edifícios, tendendo ao plongée ou ao contre-plongée; amenização da presença de certos espaços conhecidos, a partir de certa ambigüidade, como o caso do Viaduto do Chá, a Praça do Colégio e a Praça do Patriarca; a brevidade de cada plano; bem como a simetria da faixa de pedestre, que rima com as repetições de certas linhas paralelas, presentes nos edifícios da paisagem urbana.

A necessidade de afirmação da mobilidade, e do trânsito seguro, pela região, nos remete à ação defendida pela Associação Viva o Centro, identificada à remoção dos entraves à reprodução do espaço como mercadoria. Como sugerido por Frugoli Jr., a ação da Associação Viva o Centro toma a presença de classes populares no centro como uma ocupação residual, que deve ser afastada, junto com uma reconfiguração do sistema de transporte coletivo, que por sua vez permite "uma presença popular em massa desnecessária"17. Algo em consonância com algumas intervenções do Estado, e do setor privado, investindo na cultura e realizando certas modificações urbanas, de maneira a varrer os empecilhos para a valorização do espaço.

Para analisar o uso de imagens-ícones de São Paulo pela publicidade atual, podemos recorrer a alguns dos trabalhos de Marcos Jorge pela Margarida Filmes. Em duas campanhas, para o Banco do Brasil e para o Ministério da Saúde, imagensícones de São Paulo sucedem-se para sugerir uma feliz união do diverso.

Na publicidade "MJ Balanço", realizada por Marcos Jorge para campanha do Banco do Brasil, a instituição financeira é colocada como um dos bastiões da economia, resistindo ante a crise internacional. As principais idéias do comercial são: ordem, resistência e fluidez. Para tanto, o ponto de partida é a própria cidade de São Paulo, com planos de skylines de prédios irreconhecíveis, que culminam com um contre-plongé do prédio do Banespa e a imagem do Copan, também em contre-plongé. A imponência e o brilho da construção de Niemeyer fecham um bloco de imagens urbanas dominadas pelo fluxo das nuvens e dos carros apresentados em fast motion. Trata-se de uma cidade plástica, que exige um olhar predominantemente receptivo e não explorador. A sucessão de planos urbanos parte do centro, local de passagem e associado à crise pela voz over (do diretor de teatro Antônio Abujamra), para imagens-ícones da cidade, Banespa e Copan cintilantes, representando a resistência o poder de colonização do Estado. A passagem entre estes dois espaços é acompanhada pela voz over, que no início refere-se à crise financeira, sob as imagens do centro urbano, e pouco depois, anuncia o poder do Banco do Brasil, sob as imagens do prédio do Banespa e do Copan. A partir do movimento, das imagens urbanas e das significações atribuídas pela voz over, pode-se pensar no centro como local a ser superado, e que num futuro próximo poderá ter famílias habitando, com a ajuda do crédito Imobiliário do Banco do Brasil. Consumidores estes que, no comercial, aparecem numa casa cenográfica, situada ainda fora do centro urbano. 
${ }^{18}$ Produção Rede Globo; direção Maurício Farias e Mauro Farias.

${ }^{19}$ Produção Rede Globo; direção de Tande Bressane, Tadeu Jungle e Bruno Barreto.

${ }^{20}$ Co-produção $\mathrm{O} 2$ filmes e Rede Globo; direção geral de Fernando Meirelles. A série também foi para as telas do cinema, em versão dirigida por Fernando Meirelles e Toniko Melo Som e fúria (2009).
Na publicidade "MJ Balão", também realizada por Marcos Jorge, agora para campanha do Ministério da Saúde em incentivo à doação de órgãos, perseguimos um balão vermelho, em forma de coração, que une fragmentos da São Paulo central, partindo da Av. Paulista para chegar ao Copan. O coração vermelho brilhante, simbolizando a solidariedade, une prédios conhecidos e planos ambíguos da cidade, num movimento que alude à união do diverso. Temos assim o vão do túnel de acesso e reflexos de prédio na Av. Paulista, imagens diversas de uma São Paulo quase reconhecível, os prédios nas bordas da Praça Roosevelt (com referência à multiplicidade cultural), o prédio do Banespa, Ed. Martinelli, janela com vista distante do que parece ser o vale do Anhangabaú e, finalmente, o prédio do Copan, cuja parede é escalada pelo balão, até as mãos de uma criança que vive com um coração doado. Aqui, a cidade é união de fragmentos em prol de um gesto de caridade, que une espaços associados à riqueza, à diversidade cultural e o emblema Copan, espaço de conquista, salvação e felicidade, habitado por uma humilde mãe com seu filho.

\section{Minisséries: o caso Amor em 4 atos (2011)}

Nos últimos anos, o centro de São Paulo está cada vez mais presente em novelas, mas sobretudo em algumas das minisséries, exibidas na Rede Globo. Em novelas, o mais comum e recorrente é o uso de planos da cidade como elementos de passagem, breves flashes de paisagens urbanas em fast motion, inseridas entre os diferentes blocos ou núcleos narrativos. Em algumas minisséries, porém, os espaços do centro ganham outra visibilidade e uma função narrativa mais importante. É o caso de séries como: Aline (2009-2011) ${ }^{18}$, Amor em 4 atos (2011) $)^{19}$ de certa maneira em Som e fúria $(2009)^{20}$. Em tais trabalhos, percebemos um centro reurbanizado, habitado por uma classe média "descolada" de artistas, profissionais liberais e funcionários de grandes empresas, e que atribui a tal espaço traços de status, distinção e de realização de desejos. Em outras palavras, nos dramas pessoais de personagens com considerável densidade psicológica, a região central da cidade se coloca como palco dos conflitos e como espaço de projeção dos desejos.

A minissérie Amor em 4 atos, co-produzida pela Academia de Filmes e apresentada pela TV Globo no início de 2011, propõe figuras particulares da gentrificação, associadas às possibilidades do encontro, ambientadas na região central. Em termos narrativos, exploram diferentes misturas entre as linguagens da publicidade e do melodrama. Ou seja, por um lado técnicas de animação e enquadramentos, bem como uma seleção de espaços, em sintonia com aqueles das publicidades da Margarida Filmes e da Academia de Filmes. Trata-se de uma sintonia espacial, principalmente, quanto ao uso de locais-ícones, como a Estação da Luz, a Praça Roosevelt, o Copan e o Viaduto do Chá. Por outro lado, há um flerte com traços melodramáticos, já em uso pela televisão no Brasil. Colocandose como gênero voltado às massas, o mesmo inclui: a busca pela expressividade psicológica; a ênfase à superfície do mundo, aos gestos e à expressividade da voz; a sucessão de detalhes enganadores ou reveladores; a ênfase temática aos laços de família; a formalização de um imaginário que dá corpo a uma moral, provendo a sociedade de uma pedagogia sobre aquilo que deve ou não ser feito ${ }^{21}$.

Inspirados na obra do compositor Chico Buarque, possuindo entre seus diretores Tande Bressane, Bruno Barreto e Tadeu Jungle, três dos quatro episódios de Amor em 4 atos trazem histórias de habitantes e trabalhadores do centro paulistano. As imediações do Bairro da Luz e da Rua Augusta servem de palco para os encontros amorosos dos personagens. O primeiro episódio, Ela faz cinema, dirigido por Tadeu Jungle, merece destaque. A Estação da Luz e o Parque da Luz são apresentados como espaços do desejo, palcos para o encontro de casais, como aquele formado por um pedreiro "boa pinta" (Malvino Salvador) e uma vídeoartista Letícia (Marjorie Estiano). Em termos da intriga, o problema colocado é a união amorosa, motivada pelo poder do acaso. A moça, apesar de comprometida, 
finge ser solteira; o rapaz, apesar de pedreiro, finge ser proprietário de um dos apartamentos do prédio, situado em frente à Estação da Luz. A ordem colocada é aquela dos fingimentos. Na seqüência do primeiro encontro entre os dois, a sós, percebe-se o lema central do filme: a sorte como alavanca do encontro que, por sua vez, corresponde à própria descoberta da Luz como espaço a ser habitado e consumido. Tudo isso, evidentemente, por meio de uma narrativa que inclui diálogos com a linguagem publicitária, usados com relativa ambigüidade. Verificamos, assim, o interesse sexual, ou atração-fetiche entre uma jovem e um pedreiro; a associação mulher-cerveja; bem como a visão panorâmica da torre da Estação e do Parque da Luz, vista pela sacada do apartamento, no momento em que o pedreiro verbaliza o seu desejo de morar numa região como aquela. Outros elementos do universo publicitário despontam, aqui e ali, também soando fake, como uma publicidade que não se realiza totalmente.

Em termos narrativos, o episódio Ela faz cinema é pontuado do início ao fim por uma voz over, que sugere os pensamentos dos personagens e interpreta situações. O poder do acaso é colocado sempre e primeiro lugar: para unir pessoas, para revelar mentiras que podem ser superadas, ou ainda, apresentado como invenção dos próprios personagens, em sua busca pela realização amorosa. Tal voz assemelha-se a uma voz das ruas, que legisla sobre tudo. Ela esconde a própria identidade, assemelhando-se a uma rádio-novela, ou a muitas das publicidades televisivas de carros. No final do episódio, porém, quando os personagens comemoram o encontro, em frente à Estação da Luz, o emissor de tal voz revela-se na pele de um homem-placa, que reafirma a importância do acaso, ironiza a presença da voz over e passa a integrar-se à festa promovida pelos demais, como representante de uma classe trabalhadora menos abastada.

Em Ela faz cinema, portanto, a região da Luz apresenta-se como local dos encontros fortuitos e do convívio de diferentes classes sociais. As pontuações da voz over, explicitada no final do filme como voz da rua, coloca o próprio acaso com ética definidora das relações e da habitação nos espaços da Luz. Embora não exista uma oposição entre bem e mal, pode-se identificar um desejo pelo centro urbano, que avança paralelamente aos encontros amorosos, colocados como sentimentos sinceros. Tal tendência é contrabalanceada pela sensação fake promovida pelos próprios traços publicitários que ambicionam uma auto-denúncia. Neste sentido, as tomadas aéreas, contre-plongées e referências à Estação da Luz como local do encontro, no contexto do episódio Ela faz cinema, sugerem uma cidade ambígua, a meio termo entre obra e produto, colocando-se como obra serial que expõe um espaço-foco de intervenções urbanas, mas joga com a auto-denúncia criativa.

Os dois últimos episódios, Folhetim e As Vitrines, são dirigidos por Bruno Barreto. Embora os personagens desloquem-se por áreas mais nobres, como a Av. Paulista, o imaginário do centro como local sensitivo e de encontro continua predominante. Os dois episódios apresentam a história de Ary, um funcionário da Caixa Econômica que se separa da esposa. A Rua Augusta, com seus bares, inferninhos e motéis, passa a ser o centro da vida afetiva do personagem. Tratase de um espaço de reconstrução, estimulando o afogamento das mágoas e a abertura para novos amores.

No episódio Folhetim, depois de uma briga com a esposa, Ary perde-se pelas casas noturnas da Rua Augusta. Ali, o funcionário desquitado conhece Vera, uma jovem prostituta por quem se apaixona. A partir de então, a história se desloca para regiões centrais da cidade. Em algumas cenas, novamente percebemos o centro de São Paulo transformar-se num espaço humano e desejado. É o caso da longa caminhada de Vera e Ary, entre a Rua Augusta e o Viaduto do Chá. O deslocamento em direção ao centro corresponde a uma imersão na intimidade de Ary. Trata-se de um movimento em busca de um amor correspondido, ou ainda, de uma mulher para sempre desejada. No viaduto, o beijo entre os dois ganha a forma de dois travellings 
descendentes, tendendo a um contre-plongé e que destaca o próprio viaduto e o Shopping Luz: espaços do desejo e do encontro, numa cidade internacionalizada, cujos cartões postais correspondem a locais da realização amorosa.

No episódio As vitrines, Ary aluga um apartamento do Copan para morar. Por coincidência, reafirmando a ação do fortuito nos amores da São Paulo Central, Vera é sua vizinha da frente. Ele consegue conquistá-la, dizendo-lhe que gostaria apenas de vê-la passar. A trama gira em torno da busca de Ary por Vera, incluindo diálogos com o universo publicitário sobretudo por meio do trabalho de iluminação. Seja nos bares da Rua Augusta, seja na seqüência do primeiro olhar de Ary para Vera no hall do Copan, nota-se um elaborado trabalho com neons e definição de tonalidades, com possíveis inspirações no universo publicitário. No meio do filme, um fast motion de carros na Av. Paulista também remete-se ao universo publicitário. No caso de As vitrines, o prédio do Copan é selecionado como espaço-ícone, palco de uma história de amor, entre personagens de classes sociais diferentes: ele funcionário, ela bailarina. No final, algo é desvendado. $\mathrm{O}$ espectador descobre que o trabalho de Vera como prostituta devia-se a um traumático suicídio, do ex-noivo no dia do casamento e que possivelmente foi superado a partir do encontro com Ary.

A partir da análise de uma seleção de publicidade do Grupo INK e da Minissérie Amor em 4 atos, produzida pela Academia de Filmes, portanto, identifica-se uma gama de imagens e figurações da gentrificação que reafirmam ou criam reverberações criativas da re-apropriação da cidade. No campo publicitário, há maior sintonia com a idéia de uma cidade colocada à venda (Cf. ARANTES, 2012) a partir de operações de marketing, que partem do espaço, mas influenciam a própria produção de imagens publicitárias da cidade de São Paulo, interferindo num mercado simbólico daquilo que pode ou não ser visto. Não tratamos aqui da efetividade de tais imagens como motivadoras de um desejo de compra sobre o centro da cidade, o que exigiria um estudo qualitativamente diferente, possivelmente complementar ao trajeto aqui realizado. Em termos figurativos, destacaram-se duas formas de transformação do espaço da cidade, próprios à publicidade: a tendência à des-identificação, equiparando-se São Paulo a uma

22 Termo usado por Sassen (1998), no contexto de uma economia globalizada, para identificar aquelas cidades que competem entre si em busca de uma fatia maior no mercado global, abrigando também processos transnacionais com múltiplas localizações. Em termos de paisagem, tais cidades são marcadas pela presença de grandes arranha-céus, novas formas arquitetônicas, novas leis de zoneamento e novos princípios de gentrificação, que muitas vezes modificam sua identidade espacial, para projetar uma não-identidade transnacional. "cidade global"22, e o uso de espaços-ícones, com o significado de potência ou de união do diverso. No contexto da minissérie Amor em 4 atos, verificam-se variações em torno da figura da cidade desejada e dos locais-ícones como espaços do acaso da realização amorosa. A mescla de linguagens, envolvendo melodrama e publicidade, sugere uma reapropriação mais complexa e criativa da cidade, com variadas tensões entre os seus caracteres lúdicos de obra e seriais de produto. Focalizados no caso específico do Grupo INK, os resultados aqui apresentados fazem parte de uma pesquisa mais ampla, e em curso, de mapeamento das figuras da gentrificação em publicidades e minisséries, que abrange outras empresas de produção flexibilizada: em particular a 02 e a Conspiração Filmes, cujos materiais audiovisuais colaboram com uma gama mais ampla de figuras e tensões diante do processo de requalificação urbana em curso.

\section{Referências Bibliográficas}

ARANTES, Otília. Barcelona e Berlim: duas imagens estratégicas. São Paulo: Annablume, 2012.

ARANTES, Otilia; MARICATO, Ermínia; VAINER, Carlos. A cidade do pensamento único: desmanchando consensos. Petrópolis: Vozes, 2000.

AUMONT, Jacques. À quoi pensent les films? Paris: Ed. Seguier, 1996.

BELMANS, J. La ville dans le cinema. Bruxelas: A. De Boeck, 1977. 
BERNARDET, J-C; GROSTEIN, Marta D.; MEYER, Regina P. Cinema e metrópole: o caso paulistano. 1994. Curso realizado em cooperação ECA/USP - FAU/USP, transcrito por Glênio Nicola Povoas.

BRENEZ, Nicole. De la figure en général et du corps en particulier: I'invention figurative au cinema. Paris: De Boeck Université, 1998.

Seguier, 2006.

Traitement du lumpenproletariat par le cinema d'avant-garde. Paris:

CLARKE, D. B. (Org.). The Cinematic City. Londres: Routledge, 1997.

COMOLLI, Jean-Louis. La ville filmée. In. Vior et pouvoir. Paris: Verdier, 2004. p.545-551.

DEBORD, Guy. La societé du spectacle. Paris: Gallimard, 1992.

FRUGOLI JR., Heitor. O projeto Associação Viva o Centro e as classes populares. V Seminário da história da cidade e do urbanismo. PUC-Campinas, 1997.

GAZOLLA, Ana. Espaço e imagem. Rio de Janeiro: UFRJ, 1994.

GLASS, Ruth. Introduction to London: Aspects of change. Center for Urban Studies: London, 1963.

HAMNET, Charles. Les changements sócio economiques à Londres. Societés Contemporaines, n. 23, 1995, p.15-32.

HARVEY, David. A condição pos-moderna. São Paulo: Loyola, 1994.

. A produção capitalista do espaço. São Paulo: Annablume, 2005.

JAMESON, Fredric. The geopolitical aesthetic. Cinema and space inthe world system. Indiana: Indiana University Press; Londres: British Film Institute, 1992.

KRACAUER, Siegfried. O ornamento da massa. São Paulo: Cosac Naify, 2009.

LEFEBVRE, Henri. Le droi a la ville. Paris: Antropos, 1968.

. La presence et l'absence: contribution a la theorie des representations. Paris: Casterman, 1980.

MARICATO, Ermínia; FERREIRA, João Whitaker. Operação Urbana consorciada: diversificação urbanística participativa ou aprofundamento da desigualdade? In. OSORIO, Letícia Marques. (Org.) Estatuto da cidade e reforma urbana. Porto Alegre: Sergio Antonio Fabris Editor. 2002. p.215-250.

ROLNIK, Raquel. A cidade e a lei. São Paulo: Studio Nobel/Fapesp, 1997.

SASSEN, Saskia. As cidades na economia mundial. São Paulo: Estúdio Nobel, 1998.

SEMPLA. Plano Diretor estratégico do município de São Paulo 2002-2012. São Paulo: SENAC/ Prefeitura de São Paulo, 2004.

SMITH, Neil. The new urban frontier - Gentrification and the revanchist city. Nova York: Routledge, 1996.

. El redimensionamiento de las ciudades: la globalización y el urbanismo neoliberal. In. HARVEY, D.; SMITH, N. (org.). Capital financiero, propiedad inmobiliaria y cultura. Barcelona: Universidade Autônoma de Barcelona, 2005. 
. A gentrificação generalizada: de uma anomalia local à regeneração urbana como estratégia urbana global. In. ZACHARIASEN, C. B. (Coord.) De volta à cidade. São Paulo: Annablume, 2006. P. 59-87.

WISNIK; FIX et all. Notas Sobre a Sala São Paulo e a nova Fronteira Urbana. Revista Pós, FAU-USP, 2001.

XAVIER, Ismail. O olhar e a cena: Melodrama, Hollywood, Cinema Novo, Nelson Rodrigues. São Paulo, Cosac \& Naify, 2003.

ZUKIN, Sharon. The cultures of cities. Cambridge: Blackwell, 1995. 